\title{
MERCADO NACIONAL DE INFORMAÇÃO DIGITAL AGROECONÔMICA*
}

\author{
Margarete Boteon ${ }^{\S}$ \\ Geraldo Sant'Ana de Camargo e Barros ${ }^{\alpha}$
}

\begin{abstract}
RESUMO
O estudo analisa o mercado nacional de informação digital agroeconômica. No lado da oferta, o referencial teórico utilizado é o da Economia da Informação, enquanto o da demanda é baseado em um modelo de maximização de lucro que considera a informação um insumo. Empiricamente, avaliaram-se os sites com conteúdo agroeconômico brasileiro, e a estimativa da função de consumo foi feita com dados obtidos de questionários aplicados aos agentes do agronegócio entre outubro de 2002 a janeiro de 2003. A conclusão geral foi que as empresas de informação, para se manterem viáveis na internet, precisam ampliar a receita e o número de assinantes. Elas pouco aproveitam a tecnologia da internet para praticar arranjos mais criativos de discriminação de preços. Os resultados das estimativas de demanda indicam que os agentes ligados ao agribusiness consomem mais informação digital que os produtores. Além disso, a escolaridade apresenta-se como uma barreira para o acesso a esta tecnologia.
\end{abstract}

Palavras-chave: economia da informação, mercado digital, informação agroeconômica, internet.

\begin{abstract}
The objective is to analyze the market for Brazilian digital agricultural economic information. The theoretical analysis of the supply is through the Economics of Information and the demand is through a model that the information is considered an input to maximization the profit. Data were collected through the list of sites of Brazilian internet service providers to analyze the supply side. On the demand side, data were collected through the application of a questionnaire with the endusers of internet between October of 2002 and January of 2003. The general conclusion is that the private companies to remain in the internet need to increase receipts and the number of subscribers. They take little advantages of this technology to practice creative arrangements of price discrimination. Estimates of the consumption functions indicate that the nonfarm agribusiness consumes more digital information than the farmers. The level of education presents a restriction to access to this technology.
\end{abstract}

Key words: economic information, digital markets, agricultural economic information, internet.

JEL classification: L86, Q13.

\footnotetext{
Artigo baseado na tese de doutorado da primeira autora sob a orientação do co-autor.

$\S$ Doutora em Economia Aplicada pela ESALQ/USP. Pesquisadora do Cepea/ESALQ-USP. C.P. 132 - CEP: 13.400-970. Piracicaba-SP. E-mail: maboteon@esalq.usp.br

a Prof. Titular do Departamento de Economia Administração e Sociologia da ESALQ/USP. Coordenador do Cepea/ESALQUSP. C.P. 132 - CEP: 13.400-970. Piracicaba - SP. E-mail: gscbarro@esalq.usp.br 


\section{INTRODUÇÃo}

O presente trabalho analisa o mercado nacional de informação digital agroeconômica, tendo como objetivo geral avaliar aspectos da sua oferta e da sua demanda. Especificamente, pretende-se, do lado da oferta, analisar os produtos, serviços e modelos de negócios adotados pelos produtores e distribuidores de informação e, do lado da demanda, caracterizar o perfil dos consumidores de informação digital representados pelos agentes econômicos ligados ao agronegócio.

A justificativa para tal estudo está na importância que a informação agroeconômica representa no processo de tomada de decisão dos agentes do agronegócio. Com o advento da internet, a oferta de informações e, principalmente, a facilidade de acesso a elas aumentaram significativamente.

No agronegócio brasileiro, a tendência não foi diferente; o número de sites aumentou substancialmente nos últimos anos. No final de 1999, o número de endereços eletrônicos nacionais agropecuários era 600; após três anos, o número chegou a 2.878 (Figura 1). Desde 1999, a maioria dos endereços é institucional, com informação a respeito das empresas agrícolas ou de universidades e setor público. Especificamente com a função de processar e divulgar informação agroeconômica, o número de sites chegou, em 2002, a 117,89 de origem privada e 28 de origem pública.

Figura 1 - Evolução do número de endereços eletrônicos ligados ao agronegócio brasileiro

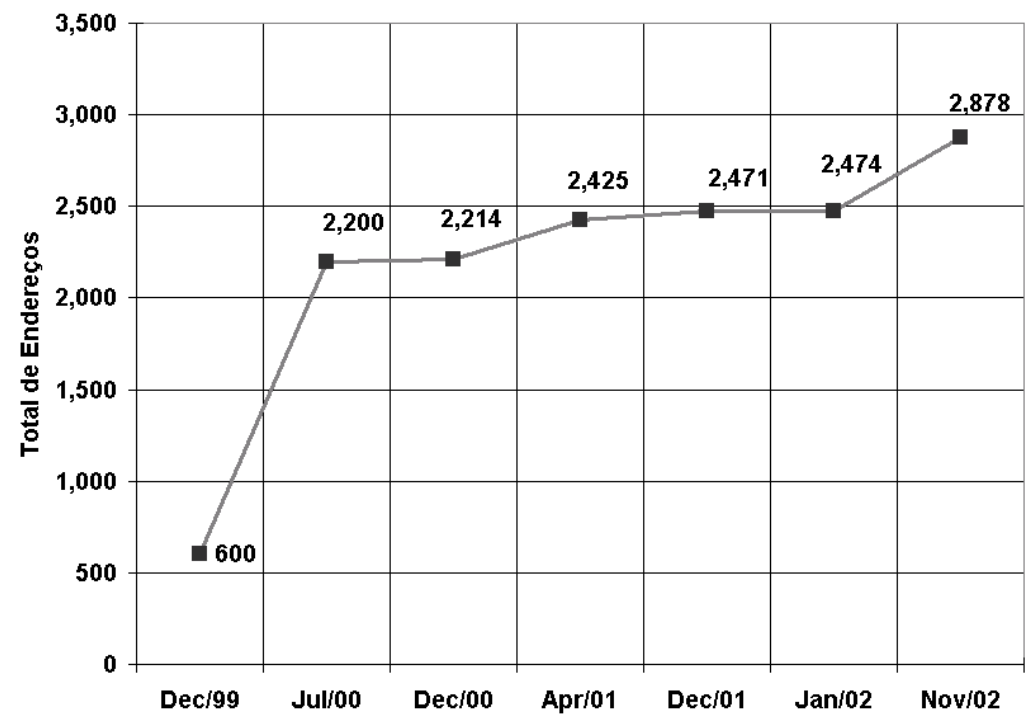

Fonte: dados da amostra.

Apesar da internet envolver questões multidisciplinares, que vão desde as ciências sociais até telecomunicações, o foco do presente trabalho concentra-se em três tópicos econômicos: oferta, demanda e valoração (preço) da informação agroeconômica. As bases teóricas deste trabalho estão descritas nas seções 2 e 3.

A aplicação empírica de todos esses conceitos é limitada pelas restritas pesquisas, informações e dados a respeito do assunto, principalmente para o agronegócio brasileiro, conhecidos até o mo-

1 A contabilização do número de sites é resultado da pesquisa do presente trabalho que acompanhou e cadastrou os endereços eletrônicos no período de 1999 a 2002. 
mento. A metodologia para avaliar a oferta e o modelo estatístico para estimar a função de demanda encontram-se na seção 4 .

Os resultados, bem como sua discussão, foram organizados na seção 5. Os resultados obtidos neste trabalho não representam o mercado de informação do agronegócio brasileiro com um todo, mas refletem a oferta de informações disponíveis na internet e a demanda do restrito grupo de usuários que possuem acesso a essa tecnologia, principalmente considerando o grupo dos produtores rurais. Na seção 6, encontram-se as principais considerações a respeito do mercado de informação digital agroeconômica brasileiro.

\section{FUNDAMENTOS TEÓRICOS SOBRE A ECONOMIA DA INFORMAÇÃO ${ }^{2}$}

Três características dificultam a transação dos bens de informação, segundo Arrow (1984): indivisibilidade, problemas de apropriação do retorno sobre a produção e bens de experiência.

A primeira característica torna os custos marginais baixos, enquanto os fixos são mais elevados e normalmente irrecuperáveis, remunerando melhor o produtor de grande escala que o de pequena. A indivisibilidade é uma característica própria dos bens de informação e significa que um indivíduo não diminui a quantidade disponível para outros. A mesma cópia de um artigo científico pode ser reproduzida pela internet milhares de vezes, com um custo muito baixo se comparado com os investimentos envolvidos para obter os resultados do estudo. A segunda característica diz respeito à dificuldade que um indivíduo tem de se apropriar dos retornos da informação, geralmente por causa desta estrutura de custo não usual. Se alguém adquirir uma informação, poderá torná-la de conhecimento geral (custo marginal baixo) e seu retorno não poderia ser apropriado pelas firmas que investiram na sua produção.

As transações também são dificultadas por outra característica: bens de experiência. Segundo Arrow (1971), há um paradoxo fundamental na determinação da demanda por informação: seu valor não é conhecido pelo comprador até que ele obtenha a informação.

Essas características levam o mercado a ser subinvestido em informação, porque as firmas compradoras enfrentarão os problemas criados pela indivisibilidade e pela dificuldade de apropriação dos retornos da informação, e os vendedores terão que arcar com as dificuldades dos compradores em julgar o valor dessa informação. A conclusão do autor é que o governo deve investir para melhorar a alocação ótima dos recursos dos bens de informação.

$\mathrm{Na}$ atualidade, o mercado acabou criando métodos para trabalhar com as características apontadas por Arrow, com a exceção da indivisibilidade que, segundo Varian (2001), é uma característica inerente aos bens da informação. $\mathrm{O}$ autor considera a dificuldade de apropriação dos retornos do investimento em bens de informação, no momento atual, uma característica menos restritiva por causa dos direitos autorais. Quanto à característica de ser um bem de experiência, a propaganda, a demonstração de parte do produto e os certificados de qualidade são estratégias que podem reduzir os problemas de o consumidor não conhecer a informação antes de obtê-la. Graças às novas tecnologias - as quais trouxeram uma espetacular redução de custos de transmissão, armazenamento e recuperação da informação - mais os investimentos privados foram captados para esse setor, favorecendo o mercado no sentido de este atuar em algumas partes do sistema de informação.

2 Em 1962, Fritz Machlup foi o primeiro autor a introduzir o conceito "Economia da Informação" e definir os setores nele incluídos. O autor dividiu em cinco grandes setores: Educação, $\mathrm{P} \& \mathrm{D}$ (Pesquisa e Desenvolvimento), Meios de Comunicação, Serviços de Informação e Máquinas de Informação (como computadores, por exemplo). A unidade básica de transação desses setores é a informação. 
Considerando a estrutura de custo, as características que dificultam a transação da informação (indivisibilidade, problema de apropriação e bem experiência), o questionamento que permanece é: como se dão a formação de preços e a comercialização de conteúdos no mercado digital? Segundo Varian (2001), a informação será raramente negociada em mercados competitivos porque nessa estrutura de mercado os preços tendem a se igualar ao custo marginal que, no caso da versão eletrônica, é próximo de zero. A estrutura mais eficiente seria de poucas empresas com poder de fixar o valor do produto, praticando discriminação de preços, e com elevada escala de produção.

A estrutura desse mercado é, segundo Varian (2001), geralmente uma competição monopolística. Devido à elevada diferenciação do produto, os produtores de bens de informação, apresentando algum grau de poder de mercado, podem recuperar seus elevados custos fixos com arranjos criativos na fixação do valor do produto, mas a falta de limitações à entrada nesse setor tende a forçar os lucros para zero ao longo do tempo.

Na literatura, duas estratégias básicas se destacam para solucionar o problema da valoração da informação: discriminação de preços por meio da criação de versões (versioning), discutida por Varian (2002), e agregação de bens via formação de pacotes (bundling), discutida por Bakos e Brynjolfsson (2001).

A estratégia de criação de versões aproveita a heterogeneidade da valoração dos bens de informação para classificar determinados grupos de consumidores, oferecendo várias versões do mesmo bem de acordo com a disposição a pagar, do grupo. A idéia é classificar os consumidores em grupos distintos de acordo com sua disposição a pagar: baixa, média ou alta, por exemplo. Os consumidores com elevada disposição escolhem uma determinada "versão", enquanto outros, com baixa disposição a pagar, escolhem uma versão de qualidade inferior. Por outro lado, a estratégia de agregação oferece aos consumidores um elevado número de bens num único pacote. Esse pacote reduz a diversidade da avaliação dos diferentes consumidores, de modo que, no limite, os vendedores fixam um único preço. Ambas as estratégias podem, de certa forma, ser consideradas como um tipo de discriminação de preço. A diferença é que a versão aumenta o "menu" de valores para se ajustar à heterogeneidade da distribuição da valoração do consumidor, enquanto o pacote reduz o efeito da heterogeneidade na disposição a pagar, oferecendo um único preço baseado na valoração média do consumidor para um determinado bem.

Segundo Shapiro e Varian (1999), a tecnologia de informação na internet permite variações sofisticadas das estratégias discriminadas no parágrafo anterior. Por exemplo, tem-se o chamado "pacote personalizado". Neste, o usuário escolhe um conjunto de categorias; o software reúne os artigos que se enquadram nessas categorias, permitindo que ele crie o próprio pacote de artigos. Outro exemplo: a tecnologia pode definir o comportamento do indivíduo, por exemplo, pelo seu histórico de compra, permitindo aos vendedores estabelecer preços adaptados a este perfil.

Para Varian (2004), as empresas encontrarão mais atrativos na internet para um ajuste fino nos preços, abandonando a planilha de custo para a decisão de formação de preços. Brynjolfsson e Smith (1999), citados por Varian (2004), observam que os sites de comércio eletrônico revêem seus preços com mais freqüência do que o varejo tradicional.

\section{FUNDAMENTOS TEÓRICOS SOBRE A DEMANDA POR INFORMAÇÃO}

Os fundamentos teóricos a respeito da demanda por informação foram adaptados de Just et al. (2002). Os autores partem de um modelo no qual o tomador de decisão visualiza a informação como um insumo, e foi desenvolvido em três estágios. No primeiro, deve decidir-se quanto de cada 
tipo de informação disponível adquirir. Para simplificar, Just et al. (2002) consideram somente dois tipos de informação: $I_{1}$ e $I_{2}$. No segundo estágio, ele processa a informação e toma decisões na sua atividade. No terceiro estágio, o resultado da tomada de decisão é revelado e o lucro é realizado.

Como na programação dinâmica, segundo Just et al. (2002), o comportamento ótimo pode ser determinado via indução inversa. Para compreender as escolhas enfrentadas pelo indivíduo no primeiro estágio deve-se primeiramente considerar o segundo estágio do modelo, quando as decisões da sua atividade estão sendo realizadas dadas as informações obtidas de $I_{1}$ e $I_{2}$ (escolhas feitas no primeiro estágio). No segundo estágio, o responsável pelas decisões enfrenta o seguinte problema:

$$
\max _{\mathrm{x}} \mathrm{EU}\left(\prod(\mathrm{x}) \mid I_{1}, I_{2}, \gamma, \phi, h\right)
$$

onde EU (.) é a utilidade esperada, П é a quase-renda com respeito à informação (porque a informação é processada no estágio 2), $\gamma$ representa a ocupação do tomador de decisão dentro da cadeia (por exemplo, fazendeiro, fornecedor de insumo, consultor), $\phi$ representa o produto agrícola em que a firma participa e $h$ é o nível de capital humano. Quanto à variável x, ela pode representar qualquer insumo e denota a decisão do agente após a revelação da informação. Para o fazendeiro, $\mathbf{x}$ pode representar a quantidade adquirida de semente, fertilizante ou trabalho. Para um agroindustrial, $\mathbf{x}$ representa o volume de produto adquirido para processamento. Apesar de a informação ter sido comprada no estágio um, alguma incerteza pode existir quanto aos lucros, e considerar a utilidade esperada é apropriado, já que o modelo procura representar uma escala abrangente de consumidores de informação, cada um com necessidades mais ou menos específicas.

Os autores consideraram que o capital humano $(h)$, função dos agentes econômicos no sistema de produção/comercialização $(\gamma)$ e o produto agropecuário são os principais fatores $(\phi)$ que afetam a habilidade e a necessidade do uso de informação.

Dado qualquer pacote da informação $\left(I_{1}, I_{2}\right)$, a hipótese dos autores é que a solução do problema da equação (1) é $\mathbf{x}^{*}$ ou, alternativamente, a utilidade esperada é maximizada por uma variável aleatória $\Pi^{*}\left(I_{1}, I_{2}\right)=\Pi\left(x^{*} \mid I_{1}, I_{2}\right)$. Voltando para o primeiro estágio, supõe-se a resolução do seguinte problema pelo responsável pelas decisões:

$$
\max _{I_{1}, I_{2}} \mathrm{EU}\left(\Pi *\left(I_{1}, I_{2}\right)-p_{1} I_{1}-p_{2} I_{2} \mid \gamma, \phi, h\right)
$$

onde $p_{i}$ é o preço unitário do tipo de informação $i$. É importante recordar que $\Pi^{*}\left(I_{1}, I_{2}\right)$ representa a variável aleatória $\Pi^{*}$, cuja distribuição é dependente da informação comprada no estágio um.

Os autores argumentam que é necessário simplificar o modelo para compreender o impacto no uso da informação. Just et al. (2002) assumem a distribuição do lucro como normal, a aversão ao risco absoluta e constante e que as preferências podem sempre ser representadas na forma de média-variância. ${ }^{3}$ Os referidos autores reescreveram (2) como:

$$
\max _{I_{1}, I_{2}} \mu\left(I_{1}, I_{2} \mid \gamma, \phi, h\right)-\frac{r}{2} \sigma^{2}\left(I_{1}, I_{2} \mid \gamma, \phi, h\right)-p_{1} I_{1}-p_{2} I_{2}
$$

onde $r$ representa o nível de aversão ao risco. A condição de primeira ordem da solução de (3), segundo os autores, será:

$$
\frac{\partial \mu}{\partial I_{i}}-\frac{r}{2} \frac{\partial \sigma^{2}}{\partial I_{i}}=p_{i} \text { para } \mathrm{i}=1,2 .
$$

\footnotetext{
3 As pressuposições para a simplificação do modelo estão descritas no trabalho original dos autores.
} 
Este problema poderá ser resolvido para algum nível de entrada de informação: $I_{1}^{*}\left(p_{1}, p_{2}, \gamma, \phi, h, r\right)$ e $I_{2}^{*}\left(p_{1}, p_{2}, \gamma, \phi, h, r\right)$.

\section{Metodologia}

\subsection{Fluxo de informação agroeconômica digital}

O estudo da oferta está concentrado na análise de quatro tipos de informação agroeconômica que circula na internet: (1) dados de produção/comercialização; (2) cotações; (3) notícias; (4) artigos econômicos/análises. Esses quatro tipos de informação apresentam assuntos relacionados com qualquer produto agropecuário brasileiro.

O levantamento dessas empresas foi realizado entre os anos de 1999 e 2002 por meio de uma minuciosa busca e classificação de 2.878 endereços eletrônicos relacionados com o agronegócio brasileiro na Web. Neste universo, foram selecionados (novembro 2002) os endereços que apresentavam como foco principal a distribuição de informações agroeconômicas, totalizando 117 sites. ${ }^{4}$ Mediante esses endereços é possível analisar quais são as empresas, a participação do setor público versus privado, seus produtos, suas estratégias, a estrutura de mercado na qual elas se inserem para comercializar dados/informações e a precificação adotada.

Para avaliar os sites disponíveis na internet é importante diferenciar dois formatos de conteúdo: dados e informações. Os dados são definidos como a matéria-prima e as informações como um produto "refinado". Dados referem-se a números sem análise, estatísticas que descrevem o cenário atual ou o que aconteceu na última semana ou em algum período no passado. Informações são definidas como análise, textos que podem incluir previsões de mercado, discussão das tendências e análise de eventos passados.

\subsection{Demanda por informação digital agroeconômica}

Os dados foram obtidos por meio de questionários ${ }^{5}$ aplicados a diversos agentes do agronegócio entre outubro/2002 e janeiro/2003. A lista dos entrevistados corresponde ao cadastro de colaboradores do CEPEA, Centro de Estudos Avançados em Economia Aplicada ligado à ESALQ/ USP.

Este cadastro pode não representar toda a agropecuária nacional, mas fornece um corte interessante devido à diversidade de estruturas de mercado, distintas para cada produto, englobando as cadeias agroindustriais, como a hortifrutícola e pecúaria - incluindo mercados domésticos de pequena escala (hortifrutícolas) e grande escala (grandes culturas). Do total de 1.500 questionários enviados, houve retorno de $11,5 \%$.

O envio do questionário via correio eletrônico acabou pré-selecionando a amostra para um público mais específico, isto é, os que possuem computadores e encontram-se conectados à internet. Essa seleção ocorreu principalmente no grupo dos produtores. Essa tecnologia ainda é bastante restrita no setor primário e exige um grau mínimo de escolaridade e renda para sua obtenção e manuseio, razão pelo qual o nível de escolaridade ${ }^{6}$ na amostra foi elevado: $92 \%$ dos produtores e/

\footnotetext{
A lista dos sites catalogada no estudo pode ser solicitada via e-mail dos autores.

Uma cópia do questionário e do perfil da amostra pode ser solicitada por intermédio do e-mail dos autores.

6 Francisco (2003) mensurou o nível de penetração da internet entre os produtores rurais paulistas e observou perfil similar ao obtido na presente amostra quanto à escolaridade. Segundo o levantamento da autora, $13 \%$ dos produtores paulistas apresentavam grau universitário, já aqueles que utilizavam internet eram estimados em $57 \%$.
} 
ou administradores rurais apresentam, no mínimo, terceiro grau completo (acima de 11 anos de estudo) e $57 \%$ com receita anual bruta abaixo de $\mathrm{R} \$ 1$ milhão (abaixo de $\mathrm{R} \$ 100$ mil: $21 \%$; entre $\mathrm{R} \$ 100-500$ mil: 27\%; de 500 mil a $\mathrm{R} \$ 1$ milhão: 9\%); o restante, acima deste montante.

Nos demais segmentos econômicos das cadeias agroindustriais entrevistadas, como a indústria de insumos ou o pós-porteira - agroindústrias, exportadores, mídia e consultores -, o uso da internet é, de modo geral, bastante comum. Além disso, o perfil deste grupo pesquisado no presente estudo também é bastante representativo da média deste segmento, já que o nível de escolaridade dos tomadores de decisão e a receita média anual são mais elevados que os do produtor primário. Os entrevistados foram questionados a respeito da intensidade de uso e os principais veículos de acesso à informação (internet versus outros veículos de informação). A informação da internet (digital) é aquela que pode ser obtida por meio de boletins, relatórios e revistas eletrônicas, adquiridas pelo correio eletrônico ou pela rede mundial de computadores. Os "outros veículos" são as que chegam via revistas ou jornais impressos, fax, boletins via correio etc. TV e rádio não foram considerados.

Para levantar os dados, foi formulada a seguinte pergunta: Quanto ao seu consumo de informação, quais são as que chegam por meio da internet $\left(I_{1}\right)$ e qual porcentual é derivado de outros canais $\left(I_{2}\right)$ ? (O total é igual a 100\%).

Para implementar o modelo descrito na seção 3 fazem-se necessárias ainda duas considerações. Primeira, $I_{1}$ e $I_{2}$ são informações complementares, ou seja, a soma dos dois tipos de informação é igual a $1\left(I_{1}+I_{2}=1\right)$. Segunda, por ser uma amostra de dados de cortes seccionais, o preço de um determinado tipo de informação é o mesmo para toda a amostra. Sendo assim, não é possível considerá-lo para a resolução do problema. Pode-se, então, definir o uso do tipo 1 da informação como $I_{1}=f(\gamma, \phi, h, r)$ e 2 como $I_{2}=g(\gamma, \phi, h, r)$ ou, obtendo $I_{1}$, automaticamente obtém-se $I_{2}$ $\left(I_{2}=1-I_{1}\right)$. Assim, o problema será resolviao por meio da seguinte função:

$$
I_{1}=f(\gamma, \phi, h, r)
$$

O nível de escolaridade ( $h$ ) foi utilizado como proxy para avaliar o capital humano dos agentes, e encontra-se dividido em três níveis: até o ensino médio (COLE), faculdade (FACULDADE) e pós-graduação (POS).

As posições dos agentes dentro da cadeia $(\gamma)$ foram divididas em 6 categorias: produtor (PRODUTOR); agroindústrias, traders, corretoras, atacadistas (AGRI); mídia agropecuária e empresas de consultoria (INTER); agroindústrias, corretoras ou atacadistas com propriedades rurais (PROAGRI); empresas de insumos agropecuários como defensivos e fertilizantes (INSUMOS); e produtor que apresenta tanto agroindústria como empresa de insumo e é também um consultor, isto é, desempenha diversas funções ao longo da cadeia (VARIA).

Os produtos agropecuários $(\phi)$ considerados foram: grandes commodities (porém monoculturas), como café, soja, milho e cana-de-açúcar (COMMODITIES); pecuária bovina (PECUÁRIA); portfólios de produtos desde agrícolas a pecuários (DIVER), somente com portfólio agrícola (DIVERAGRI) e hortifrutícolas (HORTIFRUTI).

Conforme procedimento adotado por Just et al. (2002), toma-se a aproximação de primeira ordem de (5) com respeito ao capital humano $(h)$, commodity $(\phi)$, e sua função na cadeia $(\gamma)$ pode ser obtida da seguinte forma:

$$
\begin{aligned}
& I_{1}=g\left(\gamma_{0}, \phi_{0}, h_{0}, r\right)+g_{h}\left(\gamma_{0}, \phi_{0}, h_{0}, r\right)\left(h-h_{\partial}\right)+g_{\gamma}\left(\gamma_{0}, \phi_{0}, h_{0}, r\right)\left(\gamma-\gamma_{0}\right) \\
& +g_{\phi}\left(\gamma_{0}, \phi_{0}, h_{0}, r\right)\left(\phi-\phi_{0}\right)
\end{aligned}
$$


onde $r$ representa o nível de aversão ao risco (que se supõe idêntico para todos os indivíduos), $g_{h}\left(\gamma_{0}, \phi_{0}, h_{0}, r\right)\left(h-h_{\mathrm{o}}\right), g_{\gamma}\left(\gamma_{0}, \phi_{0}, h_{0}, r\right)\left(\gamma-\gamma_{0}\right)$ e $g_{\phi}\left(\gamma_{0}, \phi_{0}, h_{0}, r\right)\left(\phi-\phi_{0}\right)$ são produtos de vetores-linha de coeficientes por vetores-coluna de variáveis.

As variáveis explicativas, todas dummies que assumem valores 0 ou 1, do modelo são: posições dos agentes dentro da cadeia $(\gamma)$, produtos agropecuários $(\phi)$ e nível de escolaridade $(h)$. No presente estudo, os vetores de variáveis dummies são todos nulos nos seguintes casos: PRODUTOR, HORTIFRUTI, FACULDADE.

$I_{1}$ representa a variável dependente que, neste trabalho, é a proporção de informação captada da Internet (Equação 7). Como $I_{1}$ é o complemento de $I_{2}$, isto significa que os sinais opostos dos coeficientes das variáveis independentes estimadas nas equações refletem o consumo de informação por outros veículos. A equação a seguir foi estimada por meio do método de mínimos quadrados ordinários, levando em conta as hipóteses do modelo clássico de regressão linear. ${ }^{7}$

Internet $=\beta_{0}^{1}+\beta_{1}^{1}$ COMMODITES $+\beta_{2}^{1}$ PECUARIA $+\beta_{3}^{1}$ DIVER $+\beta_{4}^{1}$ DIVERAGRI $+\beta_{5}^{1}$ AGRI +

$\beta_{6}^{1}$ INTER $+\beta_{7}^{1}$ PROAGRI $+\beta_{8}^{1}$ INSUMOS $+\beta_{9}^{1}$ VARIA $+\beta_{10}^{1} \mathrm{COLE}+\beta_{11}^{1} \mathrm{POS}+\varepsilon^{1}$

\section{RESUlTADOS E DISCUSSÃO}

\subsection{Fluxo de informação digital agroeconômica brasileiro}

A data de análise dos sites foi fixada (novembro 2002) devido às mudanças de conteúdo que foram ocorrendo desde 1999 e à elevada entrada e saída de sites de origem privada ao longo do período analisado. Os endereços eletrônicos com conteúdo voltados ao agronegócio também surgiram com o boom das empresas "pontocom” na internet em 1999/2000. Do segundo semestre de 2001 até novembro de 2002, tanto a entrada como saída de sites de informação agroeconômicas diminuíram e os seus formatos tornaram-se mais estáveis.

No período da pesquisa, a informação agroeconômica foi processada e distribuída por 117 sites. A participação privada é maior em número de endereços eletrônicos do que a pública: são 89 sites contra 28, respectivamente. Quase a metade do privado (41 endereços) é representada pelas entidades e associações de classe, que distribuem fontes de informações/dados públicos e privados. O segundo, em número, é o grupo denominado "portal”, com 26 sites, que tem importante papel de compilar diversas informações disponibilizadas em jornais, setor público e entidades de classes em um único local, em geral de livre acesso. Esse grupo não tem origem na mídia. Normalmente são empresas de softwares, profissionais autônomos do setor agropecuário ou empresas de consultorias que não são especializadas em produzir informações agroeconômicas primárias. Por último, com 22 sites, encontram-se o grupo da mídia (jornais/revistas de grande circulação e agências de notícias) e consultorias especializadas em conteúdo agreconômico.

A Tabela 1 avalia a formatação do conteúdo desses sites. O conteúdo mais presente nestes endereços é, sem dúvida, constituído de cotações de preços agropecuários. Dados de safra e comercialização são distribuídos principalmente pelo setor público e entidades/associações. A distribuição de Notícias e Análises de Mercado é mais expressiva pela mídia especializada e consultorias.

7 Primeiramente foi aplicado o teste Jarque-Bera (JB) para avaliar a normalidade da distribuição dos resíduos. Para heteroscedastícia, o teste utilizado para detectar se o resíduo apresentava variância constante foi o Breusch-Pagan-Godfrey (BPG). Pode-se considerar o BGP caso a hipótese da normalidade das perturbações não seja rejeitada pelo teste de Jarque-Bera (JB). Os procedimentos estatísticos para aplicação dos testes foram baseados em Gujarati (2000). 
Tabela 1 - Tipo de conteúdo disponível nos sites de informação agroeconômica brasileiro

\begin{tabular}{lcccc}
\hline & Sites Públicos & \multicolumn{3}{c}{ Sites Privados } \\
\cline { 3 - 4 } & & $\begin{array}{c}\text { Entidades/ } \\
\text { Associações }\end{array}$ & Portais & $\begin{array}{c}\text { Mídia/ } \\
\text { Consultorias }\end{array}$ \\
\hline Tipo de conteúdo: & & & \\
Dados & & & \\
Dados Safra/Comercialização & $72 \%^{1}$ & $52 \%^{2}$ & $11 \%^{3}$ & $27 \%^{4}$ \\
Cotações & $69 \%^{1}$ & $69 \%^{2}$ & $78 \%^{3}$ & $68 \%^{4}$ \\
Informações & & & \\
Clipping & $10 \%^{1}$ & $24 \%^{2}$ & $93 \%^{3}$ & $50 \%^{4}$ \\
Notícias & $41 \%^{1}$ & $64 \%^{2}$ & $41 \%^{3}$ & $95 \%^{4}$ \\
Artigo/Análise & $52 \%^{1}$ & $50 \%^{2}$ & $48 \%^{3}$ & $73 \%^{4}$ \\
\hline
\end{tabular}

Fonte: Dados da Amostra.

1 Participação de determinado dado ou informação num total de 28 sites. ${ }^{2}$ Participação de determinado dado ou informação num total de 41 sites. ${ }^{3}$ Participação de determinado dado ou informação num total de 26 sites. ${ }^{4}$ Participação de determinado dado ou informação num total de 22 sites.

Os resultados da catalogação dos sites permitem algumas considerações a respeito da participação dos setores público e privado. Observa-se que o governo apresenta um papel fundamental no fluxo de informação agroeconômica brasileiro, principalmente na produção de dados de safra/comercialização em nível nacional. A oferta dos provedores privados ainda não é uma substituta para os dados comumente elaborados pelo setor público. Muitas vezes os provedores privados não apresentam uma metodologia rigorosa de levantamento, mas apenas impressões do mercado. A importância das fontes privadas de dados, principalmente com acesso pago, é sua maior periodicidade de atualização do conteúdo. Por outro lado, quanto à produção especificamente de cotações, em muitos setores com elevada expressão econômica ou bem organizados em entidades de classe a participação privada é, muitas vezes, uma importante fonte alternativa.

Em face da escassez de investimentos públicos nessa área, um setor que vem se organizando e constituindo um potencial substituto do setor público é o das organizações e associações de classe do agronegócio, principalmente na produção de dados. $\mathrm{O}$ advento da internet também possibilitou maior visibilidade das informações produzidas por esse grupo, antes restrito somente para os seus associados.

Quanto à mídia e consultorias, essas ainda dependem dos dados e informações produzidos pelo setor público. Seu principal papel é agregar valor a esses dados por meio de análises dos mesmos. Neste grupo, poucos são produtores de dados estatísticos de produção e comercialização, e quando assumem esta função, voltam-se para um produto agropecuário específico no agronegócio. Além disso, a oferta de informações deste grupo é direcionada para o público (produtores, exportadores, processadores e corretores) relacionado com pecuária e grandes commodities. 
Analisando especificamente o grupo dos sites privados ao qual se tem acesso mediante pagamento, pode-se constatar que é concentrado em poucas empresas. Na maioria das vezes são jornais, revistas, agências de notícias e empresas de consultorias. Contudo, para analisar a concentração de mercado e estratégia de negócios destas empresas deve-se, inicialmente, considerar o mercado relevante de cada uma. Pode-se verificar que o número de firmas em cada foco de mercado é, em média, dois (Tabela 2).

Tabela 2 - Número, mercado relevante, estratégia de venda e preços das empresas privadas de informações

\begin{tabular}{llll}
\hline Tipo e número de empresas & \multicolumn{1}{c}{$\begin{array}{c}\text { Mercado } \\
\text { Relevante }\end{array}$} & $\begin{array}{c}\text { Estratégia } \\
\text { de Venda }\end{array}$ & \multicolumn{1}{c}{$\begin{array}{c}\text { Valor } \\
\text { Anual }^{1}\end{array}$} \\
\hline $\begin{array}{l}\text { Jornal Econômico com seção } \\
\text { em agroeconomia (2) }\end{array}$ & $\begin{array}{l}\text { Tomadores de decisão de grandes setores } \\
\text { da economia, inclusive do agronegócio }\end{array}$ & Assinatura & $\mathrm{R} \$ 230,00-$ \\
$\begin{array}{l}\text { Revistas eletrônicas com foco } \\
\text { em agroeconomia (2) }\end{array}$ & Agentes do agronegócio de café & Assinatura & $\mathrm{R} \$ 1.000,00$ \\
$\begin{array}{l}\text { Consultorias com foco em } \\
\text { agroeconomia (4) }\end{array}$ & Agentes da Pecuária de corte e de grãos & Pacotes mistos & $\mathrm{R} 500,00-$ \\
Agências (2) & Mercado financeiro de grandes commodi- & Pacotes mistos & $\mathrm{R} \$ 70,00-$ \\
& ties agropecuárias & $\mathrm{R} \$ 400,0000$ \\
\hline
\end{tabular}

Fonte: Dados da Amostra. ${ }^{1}$ Valor de tabela, sem considerar promoções, coletado em novembro/02.

Analisando o modelo de negócios dessas empresas verifica-se que a maior parte adota a agregação e desagregação de produtos e serviços (pacotes). A estratégia de pacote é mais recomendada quando se trata de um grande portal, como a UOL, que capta um número elevado de clientes bastante heterogêneos (criança, jovens e adultos), com focos extremamente diversos (entretenimento a negócios). Mas, no agronegócio, o número de clientes em potencial é muito menor do que nesses grandes portais. Os focos de determinados segmentos também são bastante homogêneos, permitindo a identificação de grupos e a disposição a pagar de cada um deles. Com isto pode-se melhorar a receita, capturando tanto o excedente do grupo que tem uma disposição a pagar mais elevada como os agentes com menor disposição a pagar.

A prática mais comum de versão é a diferenciação por freqüência de atualização entre a informação em tempo real (sistemas de atualização on line de bolsas) e a relativamente “atrasada”. A lógica da criação de versões é mais ampla que este exemplo e requer do produtor de informação um conhecimento muito específico do seu público para criar diferentes versões, para diferentes segmentos de mercado.

A internet possibilita arranjos mais criativos de discriminação de preços do que os que são atualmente praticados por estas empresas, como é o caso do jornal personalizado, construído pelo próprio consumidor, ou a venda de uma determinada informação de acordo com o perfil do consumidor. Além disso, das 10 empresas de conteúdo privado e pago do agronegócio avaliadas, a maioria foca um público-alvo muito restrito do agronegócio (possivelmente o grupo com maior disposição a pagar): traders de grandes commodities com expressão no mercado externo e interno, excluindo o potencial de mercado com outros agentes e com outros sistemas de produção. 
Deve-se ressaltar que o mercado de informação digital agroeconômica brasileiro ainda encontra-se em processo de formação. A entrada na internet das empresas é recente, iniciadas em 1999. A tendência é que a tecnologia da internet possibilite estratégias de valoração do produto mais amplas do que atualmente são ofertadas pelas empresas de informação, ampliando o número de clientes e sua receita, vital para sua sustentabilidade no mercado digital.

Os recursos financeiros de fundos e de bancos no mercado digital têm sido escassos após a desvalorização da NASDAQ no primeiro semestre de 2001. A internet acabou não gerando os retornos previstos por estes investidores, reduzindo os investimentos em empresas de tecnologia. Além disso, as principais empresas de comunicação do País estão com problemas financeiros muito sérios. Segundo Dines (2003), essas empresas estão comprometidas com enormes dívidas em bancos devido a empréstimos em dólar, captados antes da desvalorização do real.

Uma última consideração importante nesta seção é a análise do ambiente no qual a informação circula: a internet. De modo geral, o principal papel da internet no agronegócio brasileiro tem sido o de facilitar o rápido acesso à informação, já que sua tecnologia facilita a busca, manipulação, armazenamento, transmissão e a recepção de forma ágil. Essa tecnologia possibilitou às empresas ligadas à informação uma redução drástica nos custos de reprodução e distribuição de conteúdo.

De modo geral, a internet acabou facilitando a distribuição da informação e ampliando a atuação dos distribuidores de informação. Muitas fontes primárias que anteriormente somente exerciam papel de produtora, atualmente também assumem o papel de distribuidoras, antes sob responsabilidade principalmente da mídia. A internet também permitiu a entrada de novas empresas intermediárias no fluxo de informação, como é o caso dos portais. Porém, ainda não estimulou o aumento do volume de fontes primárias agropecuárias - as empresas/organizações que produzem conteúdo são praticamente as mesmas de antes do advento da internet.

\subsection{Demanda por informação agroeconômica digital}

A Tabela 3 apresenta os resultados para a função de consumo de informação digital (internet). Os valores obtidos para os coeficientes das variáveis explicativas representam o uso porcentual diferencial de informação digital em comparação com a constante que representa a proporção de consumo de informação com este atributo pelo produtor de frutas e hortaliças que completou a faculdade, no caso, estimada em 48,25\%. No geral, as diferentes atividades de cada agente na cadeia e o nível de escolaridade influenciam estatisticamente mais no consumo relativo de informação digital do que o produto agrícola. Os padrões de uso da informação digital não diferem, estatisticamente, entre os tipos de culturas.

O produtor e o intermediário (mídia/consultoria) são os que utilizam relativamente menos a internet como fonte de consulta para a tomada de decisão (Tabela 3). As atividades ligadas ao agribusiness ou as empresas de insumo são as que mais demandam informação digital, independentemente da cultura. Isto significa que empresas de insumos, atacadistas, exportadores, corretores, que apresentam ou não propriedades rurais, são os que consomem mais informação digital. A explicação para o menor uso por parte dos intermediários pode estar relacionada ao tipo de serviços que eles desempenham (transformar a matéria-prima (dados) em informação personalizada) e a internet já apresenta uma informação mais processada, decodificada. 
Tabela 3 - Estimativa da função de consumo de informação agroeconômica pela internet

\begin{tabular}{llccc}
\hline & Variável Independente & Coeficiente & Teste t & Signif. \\
\hline \multirow{3}{*}{ Produtos } & Constant & 0.4825 & 11.74 & $* *$ \\
& CULTURAS & 0.0786 & 1.24 & \\
& PECUARIA & -0.0642 & -1.22 & \\
& DIVER & 0.0484 & 0.98 & \\
Atividade & DIVAGRI & -0.0822 & -1.43 & \\
& AGRI & 0.1406 & 2.56 & $*$ \\
& INTER & -0.0363 & -0.55 & \\
& PROAGR & 0.1886 & 2.97 & $* *$ \\
Educação & INSUMOS & 0.1357 & 2.35 & $* *$ \\
& VARIA & 0.1524 & 2.61 & $*$ \\
& COLE & -0.1378 & -2.39 & $* *$
\end{tabular}

* Nível de significância: 10\%; ** Nível de significância: 5\%;

$\mathrm{F}(11,160)=3.6735^{* *}, \mathrm{r}^{2}=0.2016$. O teste Breusch-Pagan-Godfrey (BPG) rejeita a hipótese de heteroscedastícia. O teste Jarque-Bera não rejeita a normalidade da distribuição dos resíduos e o teste Breusch-Godfrey (BG) não rejeita a ausência de autocorrelação.

A escolaridade também é uma barreira para o acesso à informação eletrônica, principalmente níveis abaixo de faculdade. A explicação é que a informação digital é intensiva em capital humano (requer o mínimo de escolaridade para manusear tal tecnologia). O fato, porém, de se ter ou não pós-graduação não se mostrou importante estatisticamente para o consumo de informação digital (Tabela 3).

\section{CONSIDERAÇÕES FINAIS}

Com o advento da internet - e conseqüente barateamento dos custos de distribuição e melhorias no manuseio, busca e recuperação da informação -, está ocorrendo uma maior participação do setor privado na oferta de conteúdo direcionado às culturas agropecuárias com maior expressão econômica. Os benefícios para o usuário final são uma ampla divulgação em diferentes endereços eletrônicos (públicos, entidades/associações e portais) de informação agroeconômica e de forma gratuita, na maioria dos casos. Apesar do aumento expressivo de sites, foi pequeno o aumento das fontes primárias de informação; na verdade, permanecem praticamente as mesmas de antes do advento da internet.

Avaliando o fluxo de informação agroeconômica brasileiro na $W e b$, conclui-se que o setor público apresenta um papel importante; os seus dados (estatísticas de produção e preços) permitem 
ao setor privado produzir/processar e circular notícias e análises. De modo geral, há uma divisão de trabalho na oferta de informação entre os grupos analisados. Órgãos públicos, juntamente com as entidades/associações, são os principais responsáveis pela produção de dados, enquanto a mídia e as consultorias são as que predominantemente produzem as notícias. Além disso, este último grupo, principalmente os que apresentam acesso mediante pagamento, tem uma maior periodicidade de atualização dos dados em relação aos demais grupos.

Entretanto, as empresas de informação do agronegócio brasileiro que cobram por este bem ainda não apresentam estratégias sofisticadas de discriminação de preços, que seriam facilitadas pela tecnologia da internet. Quando há arranjo de preços, observa-se, principalmente, pacotes de produtos agropecuários (agregação e desagregação). Essa estratégia acaba não captando todos os excedentes do grupo com disposição a pagar preços mais elevados, como também não aproveita a receita que poderia ser gerada com o grupo com menor disposição a pagar. A ampliação do número de assinantes desses serviços, imprescindível para melhorar a receita das empresas provedoras de informação agropecuárias na internet, só será possível com uma sofisticação das formas de se precificar, baseadas no perfil de consumidor e na sua disposição a pagar.

O presente trabalho pode contribuir para algumas considerações a respeito do perfil do consumidor de informação agroeconômica digital brasileiro, informações estas que poderiam auxiliar na formação de melhores estratégias de negócios dessas empresas. Com base nos resultados obtidos nas estimativas de consumo por informação digital, constata-se que o segmento de atuação de cada agente - por exemplo, indústrias de insumos, produtor, agroindústrias - e o nível de escolaridade influenciam mais no uso da internet do que o produto agropecuário.

Esse resultado é interessante e contrapõe-se ao desenho atual de conteúdo pela internet, que é, em boa parte, segmentado por produto agrícola. As atividades ligadas ao agribusiness e às empresas de insumos são as que mais demandam informação digital, independentemente da cultura. Isto significa dizer que empresas de insumos, atacadistas, exportadores, corretores, que apresentam ou não propriedades rurais, são as que consomem mais informação digital. O produtor é o que utiliza relativamente menos a internet como fonte de consulta para a tomada de decisão. Este resultado pode servir de subsídio na determinação dos modelos de negócio das empresas de internet, passando a definir seus grupos de público em função do segmento que ele ocupa no setor e não somente o produto agropecuário.

\section{REFERÊNCIAS BIBLIOGRÁFICAS}

Arrow, K. J. The economics of information. Massachusetts: The Belknap Press of Harvard University Press, v. 4, p. 136-152, 1984, Information and economic behavior.

. Economics welfare and the allocation of resources for invention. In: Lamberton, D. M. (ed.), Economics of information and knowledge. Harmondsworth: Penguin Books, 1971, cap. 7, p. 141-159.

Bakos, Y.; Brynjolfsson, E. Aggregation and disaggregation of information goods: implications for bundling, site licensing and micropayment systems. /Draft paper, Jun. 1997/ http://pages.stern.nyu.edu/ 〜 bakos/ (Acessado em: 10 Sep. 2001)

Brynjolfsson, E.; Smith, M. Frictionless commerce? A comparison of internet and conventional retailers. Management Science, v. 46, n. 4, p. 563-585, 1999.

Dines, A. Socorro do BNDES: o que fazer para sair do buraco. Observatório da Imprensa, 07 out. 2003. Disponível em: http://www. tvebrasil.com.br/ observatorio (Acessado em: 05 dez. 2003).

Francisco, V. L. F. S. Acesso do setor rural à internet no Estado de São Paulo. Informações Econômicas, v. 33, n. 5, p. 53-56, 2003. 
Gujarati, D. N. Econometria básica. São Paulo: Makron, 2000. 846p.

Just, D. R.; Wolf, S. A., Zilberman, D. Consumption of economic information in agriculture. American Journal of Agricultural Economics, v. 84, n. 1, p. 39-52, 2002.

Machlup, F. The production and distribution of knowledge in the United States. Princeton: Princeton University Press, 1962. 416p.

Shapiro, C.; Varian, H. R. Versioning: the Smart way to sell information. Harvard Business Review, p. 106-114, 1998.

. A economia da informação. Rio de Janeiro: Editora Campus, 1999, 397p.

. Markets for information goods. 2000. Disponível em: http://www.sims. berkeley.edu/ hal/Papers/japan/index.html (Acessado em: 10 Aug. 2001).

Versioning information goods. March 13, 1997. Disponível em: http://www.sims. berkeley. edu/ 〜 hal/Papers/version.pdf (Acessado em: 15 Ago. 2002).

. Economic of information technology. /Draft paper present to Bocconi University, Milan, Nov. 2001/ http://www.sims.berkeley.edu/ hal/Papers/ mattioli/mattioli.html (Acessado em: 5 Jan. 2004). 